\title{
Impact of Self-driving Cars for Urban Development
}

\author{
Aleksey Zomarev \\ Expert, Institute for Transport Economics and Transport Policy Studies, aliakseizomarau@gmail.com \\ Maria Rozhenko \\ Associate Professor, Vysokovsky Graduate School of Urbanism, maria_mole@mail.ru \\ National Research University Higher School of Economics, 11 Myasnitskaya str., Moscow 101000, Russian Federation
}

\begin{abstract}
$\mathrm{T}$ he advent of self-driving vehicles is no longer just science fiction conjecture but the reality of the coming decade. Various countries have already made real progress in self-driving technologies moving beyond slogans and to meaningful action - multi-country amendments to the law, for one thing. Due to the rethinking of the transport planning process and new ways to organize passengers, the urban transport system is considered a single unit, not a set of separated transport subsystems (metro, land transport, etc.). Thus far, however, there has been no extensive study of the potential urban impact of self-driving technologies upon a city and its residents.

This paper presents a methodology for the urban impact assessment of self-driving transportation, which was developed based on an appropriate analysis for the city of Moscow. To that end, the urban environment as a research

subject is described as a set of environmental, transport, technological, economic, social, and regulatory blocks of indicators. We propose to evaluate these indicators: roads congestion, need for parking spaces, changes in the employment structure, new users of automobile transport, and others. To estimate the effects on the city, we describe four scenarios for the introduction of self-driving cars, differentiated by the speed of technological introduction and the development of co-using economics. To achieve the maximum effect of self-driving technology, one needs to adopt a proactive transport policy, including a set of measures defined by a current survey.

The survey is indispensable for future research into the impact of self-driving technology upon a city. Also, the survey has practical uses for administrations responsible for urban transport policy.
\end{abstract}

Keywords: self-driving car; self-driving technology; urban environment; transportation policy; scenario forecasting; transportation and mobility management; Moscow
Citation: Zomarev A., Rozhenko M. (2020) Impact of Selfdriving Cars for Urban Development. Foresight and STI Governance, vol. 14, no 1, pp. 70-84. DOI: 10.17323/25002597.2020.1.70.84 
$\mathrm{T}$ he mass proliferation of self-driving vehicles in cities is predicted in the next decade. The technological and economic aspects of selfdriving transport are being studied the world over [Hörl et al., 2018], while certain countries (the US, Germany, France, and the UK in particular) are taking practical steps to adapt legislation and traffic rules accordingly [Hoyle, 2016; Tomtom, 2017]. In the EU, self-driving vehicles and electric buses are being tested not only on specifically allocated roads but within entire metropolitan areas [Morgan Stanley, 2013]. At the same time, self-driving vehicle technology obviously belongs in the disruptive innovations category [Christensen, 1997], that is, it is irreversibly changing the value of using a car as such. Self-driving vehicles will be available to those who cannot drive a car for health reasons or are unwilling to waste time in traffic jams [Collie et al., 2017]. The very principle of owning a car will greatly change, for example, families may stop owning several cars. Multi-agent transport modeling shows that adopting self-driving vehicles can reduce the size of the daily operated fleet by tenfold [Fagnant, Kockelman, 2014]. Paradoxically, an increased number of car trips will be accompanied by the decreased private ownership of cars and their reduced total number.

Researchers point out the many advantages of selfdriving technology, from improving vehicle efficiency and reducing accident rate to expanding the range of users and improving the environmental situation. According to Morgan Stanley, the combined effect of resource saving and increased productivity in the US economy due to the adoption of self-driving vehicles will amount to 8\% of GDP [Morgan Stanley, 2013], due to fuel economy, reduced mortality, and reduced transportation costs for goods and passengers alike. The downsides include job cuts, the parking problem, excess mileage, and a limited scope for the private use of self-driving vehicles.

Over the last three years the number of academic papers and consulting reports on self-driving vehicles and their shared use has markedly grown. [Van den Berg, Verhoef, 2016] present a dynamic model of increasing street and road network (SRN) capacity and changing costs of self-driving vehicle users' time. The model allowed for calculating the recommended self-driving vehicle subsidy rates using US and Netherlands data. [Llorca et al., 2017] demonstrated how the load on the SRN in the Munich metropolitan area will be changing using a MATSim simulation: the average travel distance and travel time increase under any scenario.

A number of studies are devoted to specific aspects of self-driving technology unrelated to their impact upon the urban environment [Martin,
Shaheen, 2016; Skinner, Bidwell, 2016]. A report by the Organisation for Economic Co-operation and Development (OECD) [OECD, 2015] demonstrated the effectiveness of car sharing services: if for a personal car the average time of use is about one hour, with the load factor of 1.2 persons per car, shared cars on average are used for 13 hours, with the load factor of 2.3 persons per car. According to a Boston Consulting Group (BCG) report [Collie et al., 2017], the total time of use for a shared car is estimated at 15 hours per day. Numerous studies estimated the changes in throughput and transport capacity using micro- and macro-modeling. For example, with the mass adoption of self-driving shared vehicles, the total useful mileage will increase by $8 \%$ [Moreno et al., 2018]. The report [WEF, BCG, 2015] examined the social aspect of self-driving vehicles' dissemination: it turned out that on average only a third of the respondents believed they would use an self-driving vehicle, with Asian countries being the most optimistic in this regard. Zakharenko [Zakharenko, 2016] presents a theoretical model for assessing self-driving vehicles' impact upon the structure of land use. This study predicts further urbanization, increased land costs in inner cities, and the need to set up special parking lots for self-driving vehicles.

In the future, urban residents' mobility is forecast to increase due to the adoption of the "mobility as a service" (MaaS) digital concept and the emergence of new transport services such as, for example, taxi-buses: ridesharing on small buses along userdefined routes [Smith, 2016]. Technology is expected to change the vehicle fleet as such, leading to an increased share of two-seater cars and minibuses. Gruel and Stanford [Gruel, Stanford, 2016] present three scenarios for the adoption of self-driving vehicles: from adaptation through changing transport behavior to transforming the car ownership model. The authors insist on the need to carefully monitor the number of cars and the extent of their usage to avoid the uncontrolled proliferation of vehicles and negative consequences such as environmental degradation, increased number of accidents, expansion of cities, and so on.

Recently researchers have shown growing interest in the prospects of self-driving vehicle sharing or shared autonomous vehicles (SAV). This format is expected to make transport services more accessible, reduce vehicle fleet size and parking lots' acreage, and users' time and financial costs. Electric cars are believed to be the most suitable for these purposes, due to their environmental characteristics. The use of electric motors in shared autonomous electric vehicles (SAEVs) will increase SAVs' efficiency in terms of user costs and the throughput of urban SRNs [Loeb et al., 2018]. 
A BCG report [Collie et al., 2017] addresses the last mile problem with SAEVs. The need to walk to the nearest available vehicle (which can be located at a considerable distance from the potential passenger) reduces the appeal of car sharing services and hinders their growth. If cars were able to cover even short distances on their own, it could significantly increase demand for them. Self-driving transport is being researched quite actively [Milakis et al., 2017], but a number of promising topics still remain outside researchers' attention [Kockelman, Fagnant, 2015].

Transportation policy significantly affects the size of the self-driving vehicle fleet and the rate of such vehicles' use, depending on the sharing format: ride sharing $(50 \%)$ and car sharing $(100 \%)$, as shown, in particular, Lisbon's experience [Martinez, Crist, 2015]. Specifically, in all scenarios the load on SRN grows, while the duration of peak periods increases from three to four hours. Using the example of Sweden, Meyer et al. [Meyer et al., 2017] describe how, with minimal investments in transport infrastructure, accessibility zones for residents can be dramatically expanded. The human factor should be taken into account too, not just technological aspects of adopting self-driving technologies, including the proper interaction with pedestrians who together with self-driving vehicles make a common ecosystem, which does not exclusively follow formal rules [Straub, Schaefer, 2018].

Along with providing a conventional description, this paper for the first time presents a comprehensive assessment of the urban environment indicators which will change with the adoption of self-driving vehicle technology. For this purpose, a model comprising transport, technological, economic, environmental, social, political, and regulatory indicator groups was used as a basis. The last of the above groups of indicators was left outside the scope of this study due to the ambiguity and low predictability of its long-term impact upon the urban environment. We mean indicators such as safety regulations and traffic rules, liability for traffic accidents, insurance, data collection and storage, compatibility with the overall transport policy, and so on. Issues related to responsibility, data collection and storage, and traffic rules and norms deserve a separate in-depth study involving relevant experts. We also do not consider purely technical indicators measuring the development of self-driving technologies and road transport in general. Since this is a "definite uncertain future", i.e. the future that will definitely come but with non-obvious consequences, the scenario method was used [HBR, 1999]. Using the city of Moscow as an example, we consider below the impact of selfdriving technology depending on the car usage model and transport policy. A number of manage- ment recommendations are suggested for various self-driving vehicle adoption scenarios.

\section{Methodology}

\section{Analysis of Urban Factors}

Self-driving vehicles' impact upon the future development of cities can be assessed using a number of indicators, which we have arranged into the aforementioned groups on the basis of the disciplinary principle (Table 1). They describe the urban and political environment, residents, governance, and technology. Such an approach to studying the impact of transport of the future on the urban environment was applied in, for example, [Parfionov, 2017].

Transport and technological indicators. The number of cars on the streets per unit of time, which equally depends on vehicle fleet and SRN size was applied as the main assessment parameter in this indicator group, calculated in absolute and relative (compared with 2017) terms. This indicator's growth given latent demand and lack of constraining factors will be proportional to the growth of SRN. If the active vehicle fleet decreases, the number of cars on the streets per unit of time decreases only slightly: according to the Lewis-Mogridge postulate, residents tend to use their personal cars more often, the freer the roads are [Mogridge, 1990]. To assess the traffic situation and the time needed to get through traffic jams, the load on SRN and traffic flow density parameters were applied. To assess the need for parking spaces, only qualitative changes in their structure, number, and location were considered.

Economic indicators. The costs of and damage from road accidents were assessed on the basis of car and driver liability insurance data, with the assumption that the ratio of accidents with varying degrees of damage and fatalities remains unchanged with a decrease in their total number. Trip costs were calculated on the basis of both constant (car value taking into account depreciation, insurance, parking) and variable (petrol and maintenance) costs.

Environmental indicators. Areas freed due to the reduced number of single-level parking lots were expected to be used exclusively for planting greenery to improve the environmental situation. The environmentally friendly urban travel parameter is associated with reduced emissions of harmful substances into the atmosphere per one person's ride and is measured depending on the ride type and peak load on SRN.

Social indicators. Sharply reduced demand for couriers and taxi drivers leads to equally reduced employment in all scenarios. The reduced accident rate 
was estimated only depending on the level of those adopting self-driving technology. ${ }^{1}$ Parameters such as social risks (number of deaths in road accidents per 100,000 people) and transport risks (number of deaths in traffic accidents per 10,000 cars) were taken into account. The involvement of new users indicator was estimated both quantitatively (ratio of the number of new users to the total number of rides) and qualitatively (service availability for low-mobility and low-income population groups, on a five-point scale).

Political indicators. General recommendations on political and fiscal measures to regulate the number of cars and their usage were prepared on the basis of the developed matrices. This aspect plays a key role in the adoption of self-driving technology [Milakis et al., 2015].

\section{Scenario-Based Forecasting}

Each indicator group was assessed within the scope of self-driving technology adoption scenarios [Litman, 2016; Ticoli, 2015] for two aspects: "penetration rate of self-driving technology" and "shared economy development". The following four scenarios were used (Figure 1):

- Stagnation: Characterized by a low penetration rate of self-driving technology and the poor development of the shared economy. This scenario implies that the transport services market lags behind the best practices of selfdriving vehicles' application.

- Sharing: Characterized by a low penetration rate of self-driving technology and the robust
Figure 1. Scenarios for the Adoption of Self-driving Vehicle Technology

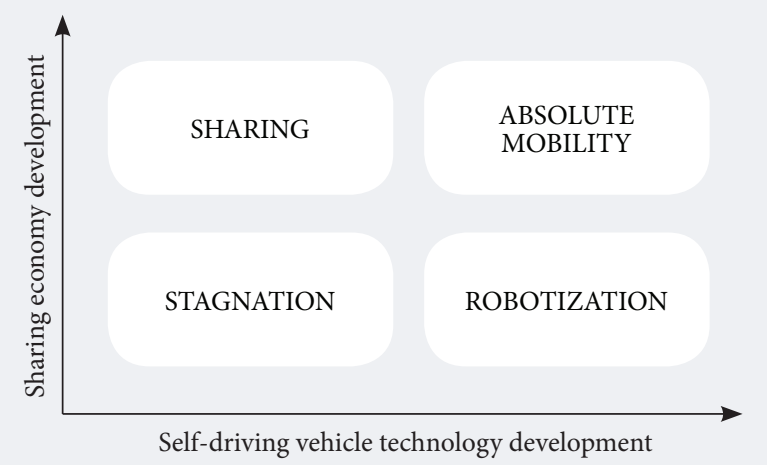

Source: composed by the authors.

development of the shared economy. This scenario provides for the further development of classic car sharing services such as ride sharing (shared car rides along a common route), etc.

- Robotization: Characterized by the rapid penetration of self-driving technology and the weak development of the shared economy. This scenario implies the gradual replacement of personal vehicles with self-driving ones, with car sharing accounting only for a small percentage of daily rides.

- Absolute Mobility: Characterized by a high penetration rate of self-driving technology combined with the robust development of the

\section{Table 1. Parameters of Self-driving Vehicles' Impact upon the Future Development of Cities}

\begin{tabular}{|c|c|c|}
\hline Indicator Groups & Studied Aspects & Parameters \\
\hline $\begin{array}{l}\text { Transport and } \\
\text { technological } \\
\text { indicators }\end{array}$ & $\begin{array}{l}\text { Impact on the traffic situation and need for space, } \\
\text { depending on the supply/demand balance for road } \\
\text { transport services }\end{array}$ & $\begin{array}{l}\text { - Traffic situation } \\
\text { - Reduced time in traffic jams } \\
\text { - Need for parking spaces }\end{array}$ \\
\hline $\begin{array}{l}\text { Economic } \\
\text { indicators }\end{array}$ & $\begin{array}{l}\text { Indirect impact of self-driving technology on city } \\
\text { budget and consumers' financial resources, depending } \\
\text { on the supply/demand balance for road transport } \\
\text { services }\end{array}$ & $\begin{array}{l}\text { - Development of related infrastructure } \\
\text { - Reduced costs of, and damage from traffic accidents } \\
\text { - Changes in property values } \\
\text { - Transport efficiency }\end{array}$ \\
\hline $\begin{array}{l}\text { Environmental } \\
\text { indicators }\end{array}$ & Environmental impact & $\begin{array}{l}\text { - Conversion of no longer needed parking lots into } \\
\text { green areas } \\
\text { - More environmentally friendly urban transport }\end{array}$ \\
\hline Social indicators & $\begin{array}{l}\text { Self-driving technologies' impact on living conditions } \\
\text { in the city and the accessibility of these technologies }\end{array}$ & $\begin{array}{l}\text { - Changes in employment structure } \\
\text { - Street and road safety } \\
\text { - Involvement of new users }\end{array}$ \\
\hline $\begin{array}{l}\text { Political } \\
\text { (regulatory) } \\
\text { indicators }\end{array}$ & Transport policy and regulations & - Management of self-driving transport services \\
\hline
\end{tabular}

\footnotetext{
To clarify: in the process of adopting this technology a temporary surge in the number of accidents due to the coexistence of vehicles driven by artificial intelligence and people is very likely to be observed, due to the differences in the decision-making mechanisms. However, to study this technology's impact on the environment as a whole, this assumption seems to be valid enough.
} 
Table 2. Basic Conditions for Self-Driving Vehicles' Adoption in Moscow

\begin{tabular}{|l|c|c|c|c|c|c|c|c|}
\hline \multirow{2}{*}{ Scenario } & \multicolumn{2}{|c|}{ Stagnation } & \multicolumn{2}{c|}{ Sharing } & \multicolumn{2}{c|}{ Robotization } & \multicolumn{2}{c|}{ Absolute Mobility } \\
\cline { 2 - 10 } & $\mathbf{2 0 3 0}$ & $\mathbf{2 0 3 5}$ & $\mathbf{2 0 3 0}$ & $\mathbf{2 0 3 5}$ & $\mathbf{2 0 3 0}$ & $\mathbf{2 0 3 5}$ & $\mathbf{2 0 3 0}$ & $\mathbf{2 0 3 5}$ \\
\hline Vehicle fleet size (thousand) & 5313 & 5676 & 2685 & 1925 & 5685 & 6073 & 2391 & 1670 \\
\hline $\begin{array}{l}\text { Motorization rate (vehicles per } \\
1,000 \text { people) }\end{array}$ & 407 & 434 & 206 & 145 & 435 & 464 & 183 & 126 \\
\hline Self-driving vehicles' share (\%) & 10 & 39 & 9 & 34 & 18 & 61 & 16 & 52 \\
\hline Source: composed by the authors.
\end{tabular}

shared economy. Under this scenario, selfdriving technology is beginning to be applied to provide car sharing services, while daily transportation by such vehicles accounts for the lion's share of total rides. In other words, transportation is carried out mainly by SAVs.

Building these scenarios, we relied both upon the published official forecasts and our own estimates [Distanz, 2017]. Forecasting comprises extrapolation (analysis of time series, trend - nonlinear) and an alternative approach where scenario building is determined by technological, economic, and demographic factors which affect the final scenario to varying degrees. In this paper, scenario modeling methods were applied (based on the forecast vehicle fleet and SRN size within the "old" Moscow city limits and the share of self-driving vehicles), comparative analysis, expert estimates, and analogies.

The basic prerequisites for self-driving vehicle adoption scenarios include the following parameters:

- vehicle fleet size;

- share of self-driving vehicles in total fleet;

- percentage of shared vehicles in total fleet;

- motorization level.

The technological impact was estimated for the long term until 2030 and 2035, that is, the probable implementation period of the forecasts used as the basis for scenario modeling. 2030 is important as the starting point for self-driving vehicle sales and their saturating the vehicle fleet over a short five- to seven-year period. 2035 remains the most chronologically distant point in the existing official forecasts: longer prospects are difficult to consider due to the poor source data quality. Still, 2035 is sufficient to assess the consequences of self-driving vehicles' arrival for the development of the city, while comparing the scenarios' basic assumptions for the above dates allows one to estimate the dynamics of changes over a five-year period for each of them.
2022 was chosen as the start of self-driving vehicle sales in the report [Morgan Stanley, 2013], but their share during the first two years remains insignificant in all scenarios since the first models on the market will most likely be purchased by car sharing companies and taxi services. During the transition period, operators will be testing self-driving vehicles' interaction with the urban infrastructure. Upon its completion, vehicle sales to individuals will begin to grow.

Data on the average load on a personal car in Moscow (1.2 passengers with an average of 2.9 rides a day, based on an online survey) was used as the starting points for scenario forecasting. New car sales growth is predicted on the basis of the expected economic growth in the Russian Federation, at $2-4 \%$ a year. With minor adjustments, it correlates with AUTOSTAT and $\mathrm{PwC}$ data [PwC, 2017]. The predicted increase in SRN throughput is based on the current trends and allows for a $20 \%$ increase by 2035 within the "old" Moscow city limits. ${ }^{2}$ The growth of the city's population is assumed to match the figure published in the Moscow Development Strategy until 2035 (13.3 million by 2035).

The "Stagnation" scenario assumes the current trends on the automotive market will continue, including the weak development of shared services (car and ride sharing), and a low share of self-driving vehicles in the total passenger vehicle fleet. The sales forecast is based on PwC's estimates for 2015 and 2016 which provide for annual medium-term new car sales growth of $7-13 \%$ and their decline in Moscow from $112 \%$ to $103 \%$ in 2022 [PWC, 2017].

According to our estimates, the share of self-driving vehicle sales on the new vehicles market will grow from $36 \%$ in 2030 to $85 \%$ in 2035 and subsequently will continue to asymptotically approach full coverage.

Taking into account the projected population growth, the motorization rate may increase to 435 vehicles per 1,000 people, with the total fleet size reaching $5,770,000$ vehicles by 2035 . 
According to the forecasted growth of sales and the share of new self-driving vehicles, under the "Stagnation" scenario, the share of self-driving vehicles in the total fleet will increase from $9 \%$ in 2030 to $34 \%$ in 2035 .

In general, the full benefits of self-driving technologies will not be obtained under this scenario even by 2035 . The share of conventional cars in the total fleet will remain at $65 \%$, while the latter is expected to grow by $35 \%$ and $47 \%$ in 2030 and 2035 , respectively, exceeding the increase in SRN. The low level of self-driving technology development in this scenario will not allow for significantly reducing the accident rate, since the probability of having an accident in a conventional car is much higher. Lagging behind in the development of vehicle sharing services will hinder the efficient use of the vehicle fleet, leading to a deteriorating road situation.

The "Absolute Mobility" scenario prioritizes the simultaneous development of self-driving vehicles and the sharing economy (car and ride sharing), with the following indicator dynamics:

- Average shared vehicle load will increase from the current 1.7 passengers per car (for taxis) [Moscow Government, 2017a] to 2.3 passengers per car, matching the best car sharing practices (e.g., in Toronto) [WEF, BCG, 2015];

- Average ride duration including waiting time for delivery of a shared car will reach $55 \mathrm{~min}$ utes by 2035, which according to HSE estimates matches the average duration of a private car ride in Moscow in 2016;

- The usage rate of shared cars will increase from the current 6.6 rides a day (car sharing) [Moscow Government, 2016] to 13.9 by 2035: with 13-hour-long daily operation, the average load of 2.3 passengers, the proper level of service (for example, in Toronto), and the 55-minute average ride duration (as in Moscow), up to 32 people will be able to use one car during the day, making up to 13.9 shared rides.

Increased supply and the growing popularity of car sharing services will lead to an outflow of passengers from the classic public transport segment and the closure of less popular routes. The redistribution will amount to 5.6 million rides per day [Moscow Government, 2017b].

This scenario describes a gradual merger of taxis and shared cars into a single (aggregate) service: the provision of self-driving public vehicles (SAVs). Such vehicles may be integrated into the "mobilityas-a-service" format which allows for setting the optimal route and choosing the best fare by identifying the passenger's current location, choosing the destination and ride type - private (one person in the vehicle) or shared with other passengers (ride sharing). Self-driving vehicles greatly increase the efficiency of programmed ride sharing, when the algorithm calculates possible routes and automatically stops the car when another request for a similar route is received. This approach to organizing self-driving transportation allows operators reduce costs and passengers to save on travel expenses. Ultimately, the popularity of this service will grow and the need for personal vehicles will decrease. Various elements of the service are being tested by various car sharing companies around the world taking into account, among other things, the prospects for applying artificial intelligence.

According to the most optimistic forecasts, if the sales start in 2022, equipping all car-sharing vehicles and taxis with self-driving technology may take 10-12 years, that is, with appropriate financial and legal support urban transport will become $100 \%$ "self-driving" only by 2034 . Under the most favorable scenario, the number of daily rides in shared cars will reach $58 \%$ of the total by 2030 and $77 \%$ by 2035 . These figures are completely consistent with the results of BCG research [Mosquet et al., 2018] according to which car- and ride-sharing in major cities will amount to $40 \%-80 \%$ of the total number of rides by 2030

The "Sharing" and "Robotization" scenarios are based on combining the basic forecast parameters of the first two scenarios depending on the importance and penetration rate of self-driving technologies, or the development of the shared economy. All scenarios are built taking into account the current trends in vehicle fleet development in Moscow.

The calculated data presented in Table 2 indicates that the same number of rides can be made with a different urban transport structure. A natural limitation for the implementation of any road transport development scenario is the SRN: fleet growth is inversely proportional to the efficiency of its use. Ensuring vehicles' availability for passengers in the "Absolute Mobility" and "Sharing" scenarios requires fewer vehicles, that is, resources are spent as efficiently as possible. In other scenarios, while the right to own a car remains in place, the motorization rate grows without a significant increase in costs. Under the "Robotization" scenario, the fleet reaches its maximum size: self-driving technologies make vehicles available to resident groups who did not have access to them previously.

Comparing the scenarios shows the futility of an uncontrolled expansion of vehicle fleet. Even given the declared increase in Moscow's SRN, it is impossible to fully meet the demand for travel by personal cars, due to the natural limitations of the city's road infrastructure. Further growth of the vehicle fleet will only aggravate the road situation, creating additional parking problems in residential areas. 


\section{Figure 2. Regulating the Vehicle Fleet Size and Vehicle Use in the City}

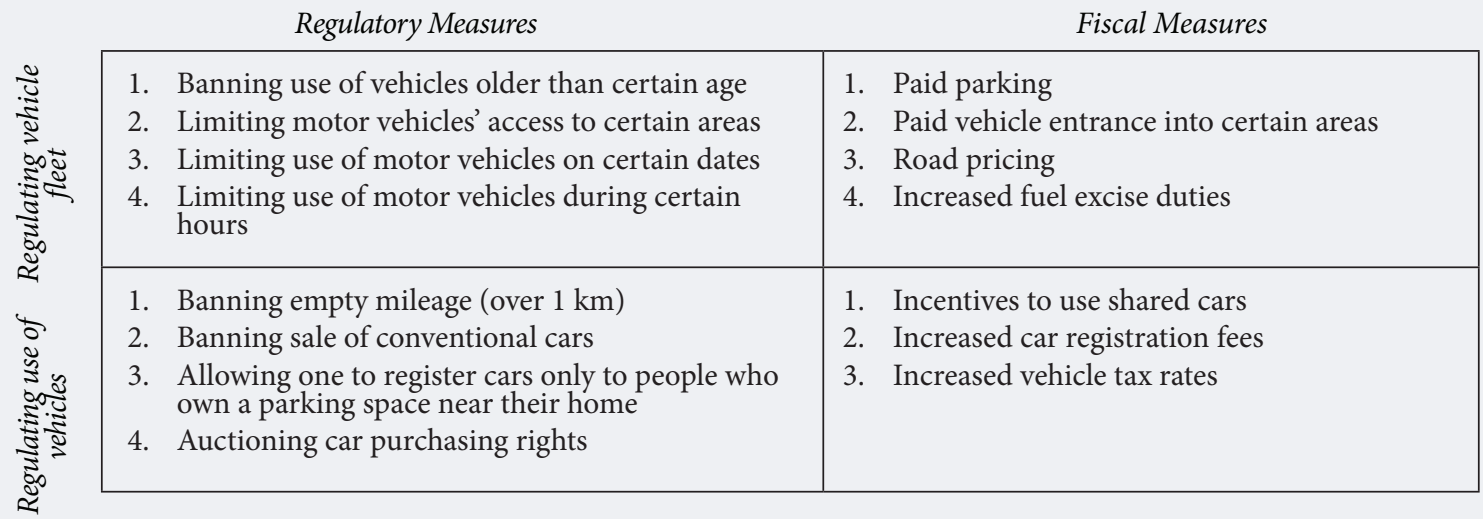

Source: composed by the authors.

The dynamics of the basic scenarios under consideration depends on which measures will be implemented in the framework of the city's transport policy. Some approaches to regulating the number of cars and their usage in Moscow are shown in Figure 2.

Achieving each scenario's target parameters requires specific urban transport policies varying in terms of the toughness of the measures applied and priorities for self-driving transport development [Li et al., 2018].

Unit ride costs in each scenario were estimated based on car prices, operating costs, and usage rate [PWC, 2016]. Vehicle maintenance costs (their estimated growth is $25 \%$ and $50 \%$ in the "Robotization" and "Stagnation" scenarios, respectively) is a kind of ownership tax on personal self-driving and conventional vehicles. Under current legislation, such an increase in maintenance costs is equivalent to increasing the vehicle tax rate by 15 and 30 times, respectively, compared with the 2017 level. Introducing a differentiated toll system (road pricing) by the calculation period of 2030-2035 along with the adjustment coefficients for the standard per kilometer rates will increase vehicle maintenance cost by the same $25 \%$ and $50 \%$ under the above scenarios. For shared vehicles, accelerated depreciation over a two year period, free parking spaces, and fixed vehicle tax rates compared with the 2017 level (or a lowering adjustment coefficient for road use tariffs) will be implemented if a road pricing system is introduced by 2030-2035, plus additional VAT for transport service operators.

Replacing conventional cars with self-driving ones leads to a gradual decrease in road accidents. When this replacement is complete, the number of accidents will be reduced by $94 \%$. We leave outside the scope of this study the question of the transport system's state while vehicles driven by artificial intelligence (which calculates how the traffic situation may develop) and ordinary cars with human drivers (who often make rash and suboptimal decisions) will be present on the roads simultaneously.

As an option to convert some of the SRN areas for non-transportation use, planting greenery (parks, gardens, etc.) is seen as the most neutral way to change urban lands' functionality, though other solutions are possible. Such areas may be used for retail, housing construction, building infrastructure, and so on. This study does not consider the environmental aspects of changing the structure of vehicles' fuel balance. Obviously the currently popular SAEV concept will develop in different countries at different rates, depending on the local technology level, availability of certain fuel types, severity of environmental problems, and the climate. Inexpensive and environmentally friendly gas motor fuel, the proliferation of hybrid engines, and climatic conditions (long periods of low temperatures) limit electric vehicles' appeal. This segment's development and further dynamics of the fuel balance structure require a separate study. To minimize uncertainty regarding the choice of the dominant fuel type for future car generations, the ride resource intensity parameter was included in the environmental section of the forecast (it is directly proportional to the way in which vehicles are used and the format of their ownership, the load on SRN, and increased environmental friendliness of vehicles' engines).

\section{Results of the Study}

The combined effect of the basic parameters of the four self-driving vehicle technology adoption scenarios in Moscow on specific characteristics of the city's environment is presented in Table. 3. 
Table 3. Summary Indicators of Self-driving Vehicles' Impact upon Urban Environment Parameters (the example of Moscow)

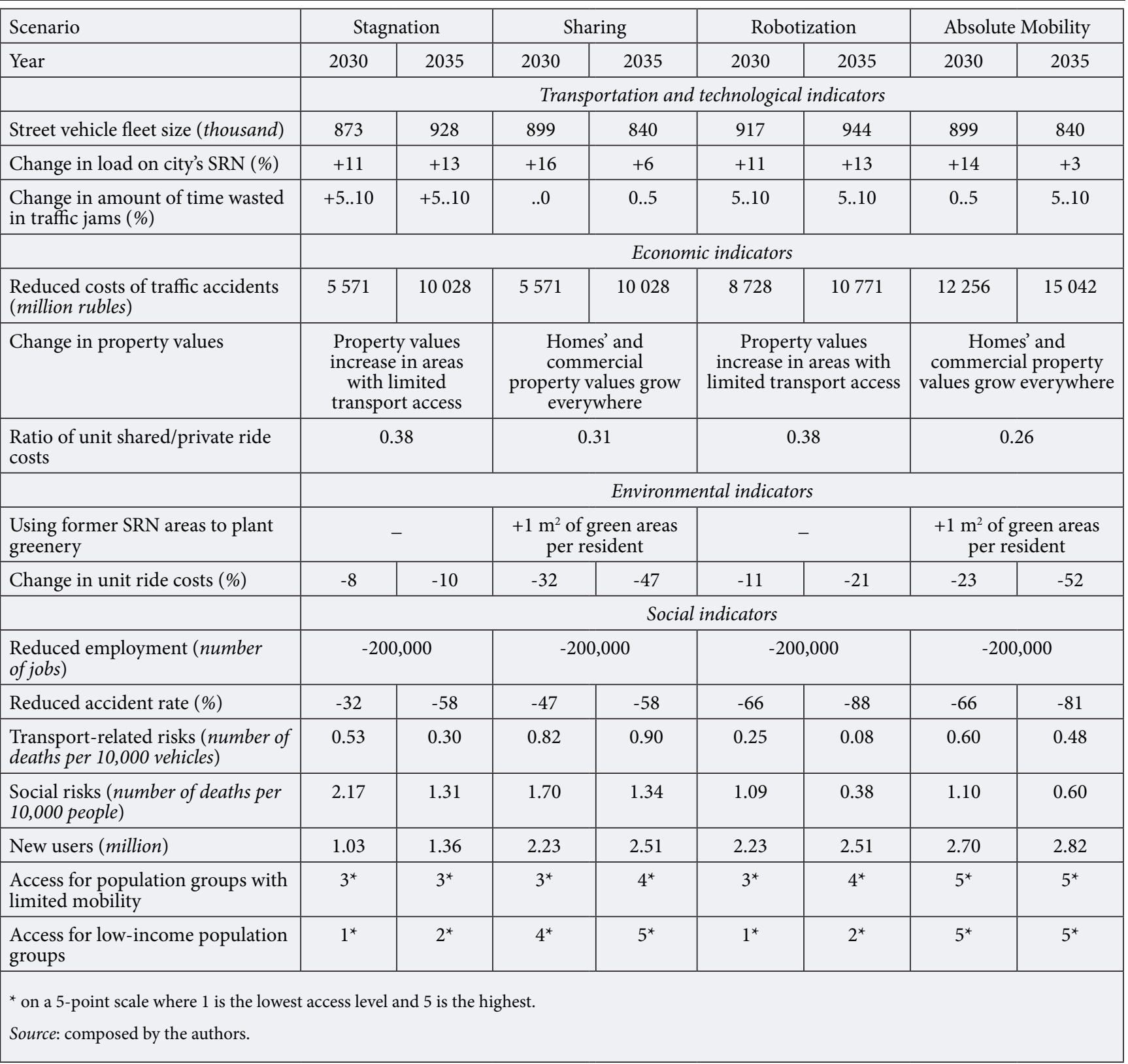

The analysis showed that the "Stagnation" and "Robotization" scenarios lead to aggravated transport problems in the city, an increased number of cars on the roads as self-driving vehicles become more available, and a deteriorating environmental situation (depending on the type of engines used). Transport-related risk measured as the number of deaths in traffic accidents per 10,000 vehicles a year will sharply decrease, from 1.5 to 0.30 and to 0.08 . The reduction in social risk (measured as the number of deaths in traffic accidents per 100,000 residents) will be equally significant, from 8.1 to 1.31 and to 0.38 for the two above scenarios, respectively. With a similar motorization level, the difference is due to the fact that the human factor remains the key cause of road accidents. According to various estimates, it accounts for up to $94 \%$ of all accidents [Skinner, Bidwell, 2016]. Self-driving vehicles will minimize the role of the human factor, with a downward effect on the overall accident rate. Under the "Robotization" scenario, which implies the highest proportion of self-driving vehicles due to their availability for a wide range of new consumers, these risks become much lower. At the same time, the load on the SRN and the amount of time spent in traffic jams will equally increase in both scenarios despite the larger total number of vehicles on the roads under the "Robotization" scenario. Programming self-driving vehicles' routes, minimizing the number of driving errors, and up- 
dating traffic information in real time will reduce the accident rate, homogenize the traffic flow, and make it more predictable. Equal unit ride costs in both these scenarios are due to the fact that the higher initial expenditures (to purchase a selfdriving car) do not allow for reducing this indicator value in "Robotization".

In both the "Stagnation" and "Robotization" scenarios, low-mobility and low-income population groups' access to transport services remains limited. For the former, the very emergence of selfdriving vehicles potentially capable of arriving to pick up a passenger on their own is more important. For the latter, the proliferation of car sharing services which offer much cheaper rides than personal vehicles eliminates the need to save and take out a loan to buy a car. Since having access to a car makes it possible to travel to jobs offering more attractive working conditions, the development of car sharing infrastructure will contribute to higher economic efficiency and better living standards, becoming a relatively inexpensive alternative to conventional public transport. However, because present-day car-sharing services are not available to users without a drivers' license, they will only be able to use the ride sharing format. Despite the high share of self-driving vehicles in the "Robotization" scenario, their convenience and maximum mobility, people with physical or financial problems will have to purchase a personal self-driving vehicle due to the insufficient development of car sharing services under this scenario. Obviously, the high costs will limit the overall access of these groups to transport services.

The "Absolute Mobility" and "Sharing" scenarios have much in common. Both imply a slightly easier traffic situation and completely solve the parking and vehicle utilization problems. Under the first scenario, transportation services for low-mobility and low-income population groups are more developed. The accident rate, waste of time, and ride costs are minimized, while the efficiency and the environmental situation are improved regardless of the engine type. Under the second scenario, the availability of transport services for vulnerable population groups is not as good. In the context of the insufficient application of self-driving technologies in carsharing, low-income individuals still need to have a drivers' license. People with limited mobility will only be able to use cars when accompanied by other people, which does, however, allow them to get by without owning a car.

The "Sharing" scenario implies a lower accident rate and a greater increase in the SRN load, since the low dissemination of self-driving vehicles does not allow for taking advantage of programmed routes. Transport risks are reduced from 1.5 to 0.48 and 0.90 , social risks from 8.1 to 0.60 and 1.34 for the "Absolute Mobility" and "Sharing" scenarios, respectively. These results are consistent with the estimates of accident rate reduction following the extensive use of car sharing (by $60 \%$ by 2030 ) [Collie et al., 2017]. The difference between indicator values under these scenarios is due to the low adoption of self-driving vehicles in the "Sharing" scenario, which reduces the human factor's impact upon the accident rate. For the same reason, unit ride costs somewhat increase, given the low adoption of self-driving technology in the scenarios. The lack of programmable routes and not taking into account the traffic situation lead to increased mileage and drivers' choosing suboptimal routes, especially in ride sharing. The latter format allows one to share travel costs and save end-users' expenses, but it is more difficult to maintain without programmable self-driving vehicles. This explains why the vehicle operation scheme in the "Sharing" scenario is less efficient than the "Absolute Mobility" scenario, where the wide application of self-driving services allows users to save travel time and not worry about finding a parking space.

Scenarios that imply the active use of shared vehicles allow one to meet higher demand for transportation with a smaller fleet. Ride sharing allows several passengers use the same vehicle at the same time. These scenarios lead to an improved (or, at least, non-deteriorating) traffic situation compared to 2017, with the increased use of vehicles.

Scenarios providing for a significant share of public cars confirm that the more popular the sharing formats are, the more environmentally neutral each ride becomes, since total per-ride energy consumption is reduced. Thus, according to the analyzed trends, per-ride resource intensity in the "Absolute Mobility" and "Sharing" scenarios is reduced by half compared with the 2017 level, due to the more efficient exploitation of vehicles, ride sharing, and more environmentally friendly engines.

Only the "Sharing" and "Absolute Mobility" scenarios imply dismantling some of the single-level parking lots. With the reduced overall vehicle fleet, the number of cars on the city streets during peak hours remains comparable in both scenarios. Therefore, the need declines not for SRN, but for parking spaces in residential areas. Converting parking spaces into green areas in Moscow will lead to an increase in green areas' acreage by one square meter per person, or by 1,600 ha in total. With the total green areas' acreage within "old Moscow" city limits of 36,100 ha in 2014, the increase will amount to about $4.5 \%$. Moreover, new green areas can be created just where people live, which will positively impact property values.

Regardless of the self-driving technology adoption scenario, the labor market will experience significant changes, mainly due to the reduced demand 
for taxi drivers and couriers, traffic police, and traffic inspectors. Up to 200,000 jobs may be eliminated, or $2 \%-3 \%$ of their total number [Business Planner, 2016].

The analysis of self-driving transport and sharing technology development based on comparing the data presented in Table 3 shows that sharing technology turns out to be the most important for the city and its residents: it allows one to deal with transport problems, ease the traffic situation, reduce resource consumption and car ride costs, and increase the number of users of this type of transport. Meanwhile the effect of self-driving vehicle technology mainly amounts to a reduced accident rate and more environmentally friendly travel (reduced resource consumption per ride).

Mechanisms for providing transport services are assessed using the management (political) indicators of self-driving vehicles' impact. The analysis is based on the experience of Asian and European cities.

Regardless of the share of self-driving vehicles, all scenarios imply the development of appropriate infrastructure at the expense of the municipal authorities or funded by a municipal-private partnership, including:

- broadband $5 \mathrm{G}$ and Wi-Fi networks with base stations at intersections;

- precision maps to support self-driving transport;

- services for marking and finding the nearest parking space;

- a network of parking hubs, to minimize mileage and the need to bring private self-driving vehicles home.

To promote the transition to self-driving transport, municipalities can introduce co-funding mechanisms (in the framework of public-private partnerships), or fully fund budget projects out of the city budget such as data processing centers (DPC) and data protection facilities (at DPCs, police departments, or independent ones) to support the uninterrupted operation of the transport system and prevent illegal interference [Maurer et al., 2015].

The "Sharing" and "Absolute Mobility" scenarios (a large proportion of shared cars) require additional services involving private companies. We mean creating a network of "mobility-as-a-service" stations required to map routes and request cars as well as specialized services (such as repair and dispatch) for public transport.

One of self-driving vehicles' advantages is the lack of a need to find a parking space. At first glance, this seems to be critically important in a city center with its high economic activity. The self-driving vehicle that delivered the passenger can move on without parking or look for a parking space on its own without human input. However, in the reality of Moscow, this would hardly be possible, especially during rush hour when dense traffic flows clog the city center, taking unpredictable routes which further complicate the situation at intersections. A logical solution seems to be introducing a ban on empty mileage above a certain limit and the active construction of automated multi-level parking lots along the perimeter of the central part of the city, to end the route of any vehicle heading to the city center without a guaranteed parking space. An alternative to the empty mileage ban can be a payas-you-go tax differentiated depending on the zone and time of day.

The scenarios with less-developed car sharing services ("Stagnation" and "Robotization") do not provide for significant changes in transport policy. These scenarios' negative effects require an adequate reaction from the city authorities, among other things to regulate the transport services market. In particular, the aforementioned multi-level automated parking lots around the perimeter of the central part of the city and in residential areas can be a solution to the parking problem and shared cars' empty mileage. In residential areas, the cost of renting a parking space near residential buildings should match or even exceed the price of parking in such parking lots to reduce the use of areas adjacent to apartment buildings for these purposes. In the absence of direct incentives for buying selfdriving vehicles, introducing an age limit for conventional cars could prompt people to change them more often. For example, cars could be automatically deregistered after 10 years in operation (the period applied in our calculations). This would lead to an increased share of self-driving vehicles and help achieve the highest potential effect of applying self-driving vehicle technology under this scenario. In the "Robotization" scenario, additional fiscal restrictions on owning a conventional car (> SAE level 4) will be applied. With underdeveloped sharing services, no benefits for SAVs are provided here either. Generally, transport policies underlying both these scenarios do not seem to be perfect for the future development of the city, for the use of space, and the efficient provision of transport services.

Scenarios that imply a significant proportion of shared cars ("Sharing" and "Absolute Mobility" scenarios) propose curbing the demand for personal cars using fiscal and regulatory methods. The first include various ways to increase the cost of owning a car. If transport legislation remains unchanged, the most effective way is to increase the vehicle tax rate. The advantages of this measure are that it allows potential buyers to estimate the additional car maintenance costs in advance. When shared 
cars are used, the tax is shared by a wider circle of users, which reduces total ride costs for each of them and encourages them to abandon personal cars. The disadvantages of the tax-based incentive include the lack of direct correlation between the vehicle's mileage and the use of SRN on the one hand and the amount due on the other. Replacing the conventional vehicle tax with a fee for the actual use of the SRN (pay-as-you-go tax) is being actively discussed now. Such a road pricing system would make it possible to differentiate the costs of using specific SRN segments depending on their condition, direction of travel, time of day, and the importance (rank) of the transport arteries. Being fairer in terms of the specific rate of SRN use, such a system would promote a more economic mode of road use and make it possible to compensate for reduced fuel tax revenues due to the increased share of electric and hybrid vehicles. However, introducing such an advanced payment system requires changing the legislation and putting in place an automated digital system to monitor the load on the SRN, predict demand, and pay the tolls, which would be burdensome both financially and technologically.

We did not try to assess the feasibility of such changes but switching to a road pricing system increases the likelihood of introducing such a system by 2030-2035. Under the "Sharing" and "Absolute Mobility" scenarios, not so much the payment procedure would matter for end users as the difference in ride costs between personal and shared cars. Thus, the currently applied vehicle tax and road pricing system will allow one to achieve comparable parameter values under both scenarios.

If in the framework of the "Sharing" scenario just the increased costs of owning a personal car turn out to be sufficient, in the "Absolute Mobility" scenario a differentiated approach could be applied, which implies the minimal costs of owning an SAV (and, with due justification of the advantages of electric models, an SAEV), and maximum ones for owning conventional cars (with the SAE autonomy level below 4).

Possible restrictive measures to curb demand for personal transportation include a legal ban on empty mileage (e.g. more than $2 \mathrm{~km}$, or $30 \mathrm{~min}$ utes), and allocating dedicated parking spaces for shared cars. The scenarios under consideration also require introducing a legal requirement according to which only people who own (or have a long-term lease of) a parking space within walking distance from their home would have the right to buy and own a private car, and regulating high capacity public transport fares to maintain its competitiveness (Table 4).
With the seemingly obvious advantages of the "Sharing" and "Absolute Mobility" scenarios, their implementation requires significant restrictions on the use of personal vehicles. Such initiatives are fraught with social costs, as they involve a forced change in the transport behavior model or significantly higher travel expenditures combined with the need to adapt to new technologies. It will not be possible to achieve these scenarios' target indicator values without the city authorities' actively working with the public to minimize the negative consequences of the decisions made and ensure that residents clearly see the future advantages. To study the latter on theoretical and practical levels, municipalities can independently fund self-driving vehicle research and use the results to justify the inevitable unpopular decisions under the "Robotization" or "Absolute Mobility" scenarios.

The potential effects of implementation the aforementioned self-driving vehicle adoption scenarios for the city as a whole and its residents in particular are presented in Table. 5.

\section{Conclusion}

Today we can confidently say that self-driving vehicles technology will be adopted in one form or another in the foreseeable future and will significantly change the very approach to transporting people and owning a car. Self-driving vehicles will lose their purely personal status in favor of the sharing model. Further, self-driving technology can positively affect the urban environment and transportation only if sharing services are adequately developed at the same time. In the next decade, car sharing and ride sharing services are expected to grow the world over and self-driving vehicles will make them especially attractive.

In the scope of our study, the role of the transportation policy in promoting the adoption of selfdriving vehicles was illustrated using the city of Moscow as an example. In the absence of restraining fiscal or regulatory mechanisms, the number of cars in personal ownership will steadily grow as the barriers limiting access to them diminish, leading to a catastrophic overload on the city's SRN. In practice, this would mean hours wasted in traffic jams, which will not allow one to fully implement self-driving vehicles' advantages. A set of measures to reduce traffic, regulate the use of urban transport, and encourage car sharing companies to purchase self-driving vehicles in bulk and change their service delivery model would help achieve a radical improvement in the traffic situation, including certain urban environment factors as well. However, the costs of this kind of improvement may turn out 
Table 4. Steps to be Taken to Accomplish the Target Parameters of the Scenarios under Consideration (the example of Moscow)

\begin{tabular}{|c|c|}
\hline Scenario & Steps to be Taken \\
\hline Stagnation & $\begin{array}{l}\text { - Prohibiting the use of cars over } 10 \text { years old } \\
\text { - Building multi-level parking lots in residential areas and along the Third Transport Ring } \\
\text { - Uniform parking rates for single- and multi-level parking in residential areas for local residents } \\
\text { - Continued support for car sharing providers } \\
\text { - Promoting the development of conventional public transport services }\end{array}$ \\
\hline Sharing & $\begin{array}{l}\text { - Registering personal cars only to people who own a parking space near their home } \\
\text { - Paid parking for private cars throughout the city } \\
\text { - Increased vehicle tax on private cars (x15 relative to } 2017 \text { rates) or introducing road pricing tool with a similar } \\
\text { increase in ownership costs } \\
\text { - Segregating parking lots in residential areas by ownership type; making parking spaces along the streets available } \\
\text { to shared cars only } \\
\text { - Increasing car sharing costs to make sure conventional public transport remains attractive } \\
\text { - + "STAGNATION" SCENARIO STEPS }\end{array}$ \\
\hline Robotization & $\begin{array}{l}\text { - Increased vehicle tax on private cars (x15 relative to } 2017 \text { rates), or introducing a road pricing tool with a similar } \\
\text { increase in ownership costs } \\
\text { - Prohibiting empty mileage (more than } 2 \mathrm{~km} \text { or } 30 \text { minutes) } \\
\text { - Promoting automated multi-level parking services in residential areas and along the Third Transport Ring and } \\
\text { petrol station services } \\
\text { - Municipalities co-fund the construction of infrastructure for self-driving vehicles (5G networks, data processing } \\
\text { centers, data protection centers, and dedicated parking lots) } \\
\text { - + "STAGNATION" SCENARIO STEPS }\end{array}$ \\
\hline $\begin{array}{l}\text { Absolute } \\
\text { Mobility }\end{array}$ & $\begin{array}{l}\text { - Increased vehicle tax on private cars (x15..x30 relative to } 2017 \text { rates) depending on SAE autonomy level (the } \\
\text { higher the level, the lower the rate) or introducing a road pricing tool with adjustment coefficients for a base rate } \\
\text { depending on the car autonomy level } \\
\text { - Making car sharing services fully available throughout the Moscow metropolitan area } \\
\text { - Municipal funding for SAV/SAEV research } \\
\text { - + "SHARING" and "ROBOTIZATION" SCENARIO STEPS }\end{array}$ \\
\hline
\end{tabular}

to be prohibitive for the public. For example, with the strongest incentives to use shared cars in place, the maintenance costs of a personal vehicle for its whole life cycle (including depreciation) would increase 50\% compared with the current rates and prices, while parking would become paid across the city all the way to the Moscow Ring Road, including territories adjacent to residential buildings.

An alternative to the traditional vehicle tax collection scheme is a more advanced road pricing system, with the rates differentiated by time and zone. Its adoption could lead to revolutionary changes, even if they are extended over a long period. We are talking about dramatic changes in the accustomed way of life occurring in a relatively short period of time, which, being extremely sensitive for the residents (users), will inevitably cause discontent and opposition.
The stronger the fiscal restrictions for owning private vehicles are, the more attractive public transport becomes, and the higher the specific efficiency of the entire fleet. Car sharing will have the highest positive effect when these services become available outside Moscow, in the near Moscow Region (Moscow metropolitan area), which will require car sharing operators to increase their capacities and cooperate with the Moscow Region services.

Our results show that the future transport policy should include both shared economy elements and incentives to adopt self-driving vehicle technology. The transport policy should be proactive, anticipating the negative consequences of the implementation of a particular scenario and keeping residents as well-informed as possible. Fiscal and regulatory measures would allow one to accomplish these objectives, the specific set of which (recommended in 
Table 5. Self-driving Vehicles' Impact upon the City and its Residents

\begin{tabular}{|c|c|c|}
\hline Scenario & Impact upon Residents & Impact upon the Urban Environment \\
\hline Stagnation & $\begin{array}{l}\text { - Affordability of personal cars } \\
\text { - Problems with keeping a car in residential areas } \\
\text { - Waste of time in traffic jams } \\
\text { - High unit ride costs } \\
\text { - Low access to road transport services for low-mobility and } \\
\text { low-income groups } \\
\text { - Loss of transportation-related jobs }\end{array}$ & $\begin{array}{l}\text { - Permanent traffic jams } \\
\text { - Acute shortage of car storage places }(+1.7 \\
\text { million cars compared with 2016) } \\
\text { - Need to build multi-level parking lots } \\
\text { - Reduced accident rate }(-58 \%) \\
\text { - Deteriorating environmental situation }\end{array}$ \\
\hline Sharing & $\begin{array}{l}\text { - Wide access to motor transport services regardless of } \\
\text { wealth and health } \\
\text { - Low- and middle-income groups abandon personal cars } \\
\text { in favor of car sharing } \\
\text { - Low travel costs, but higher than conventional public } \\
\text { transport } \\
\text { - Sharply increased costs of owning a personal car } \\
\text { - Increased mobility } \\
\text { - Loss of transportation-related jobs }\end{array}$ & $\begin{array}{l}\text { - Local traffic jams: current load on SRN remains } \\
\text { unchanged } \\
\text { - Reduced accident rate (-58\%) } \\
\text { - Improved environmental situation } \\
\text { - Increased property values in areas with limited } \\
\text { transport accessibility } \\
\text { - Slightly improved environmental situation }\end{array}$ \\
\hline Robotization & $\begin{array}{l}\text { - High appeal of owning an self-driving vehicle } \\
\text { - Low affordability of personal cars } \\
\text { - Sharply increased costs of owning a conventional personal } \\
\text { car } \\
\text { - Increased availability of motor transport services for } \\
\text { people with limited mobility } \\
\text { - Loss of transportation-related jobs } \\
\text { - Fewer problems with parking and storing vehicles }\end{array}$ & $\begin{array}{l}\text { - Permanent traffic jams with no traffic accidents } \\
\text { - Need to build automatic parking lots along the } \\
\text { Third Ring Road and in residential areas } \\
\text { - Among the highest reduction in accident rate } \\
(-88 \%) \\
\text { - Increased property values in areas with limited } \\
\text { transport accessibility } \\
\text { - Slightly improved environmental situation }\end{array}$ \\
\hline Absolute Mobility & $\begin{array}{l}\text { - Low affordability of personal cars } \\
\text { - Only high-income population groups can afford a } \\
\text { personal car } \\
\text { - Wide access to car sharing services regardless of wealth } \\
\text { and health } \\
\text { - Low travel costs, but higher than conventional public } \\
\text { transport } \\
\text { - Loss of transportation-related jobs } \\
\text { - Increased social tension, dissatisfaction with the transport } \\
\text { policy } \\
\text { - Increased mobility }\end{array}$ & $\begin{array}{l}\text { - Reduced road congestion, highly predictable } \\
\text { travel } \\
\text { - Among the highest reduction in accident rate } \\
(-81 \%) \\
\text { - Highest improvement in environmental } \\
\text { situation } \\
\text { - Increased commercial and home property } \\
\text { values across the city } \\
\text { - Opportunity to convert unused SRN areas }\end{array}$ \\
\hline
\end{tabular}

the study for inclusion in such a proactive policy) will lead to the increased total costs of owning a car and create administrative barriers to purchasing personal vehicles. These measures should be introduced gradually and be announced in advance, several years before the relevant decisions enter into force.

It was demonstrated that the current policy remains ineffective, as it causes the uncontrolled growth of the personal vehicle fleet in the city and requires an adequate expansion of the SRN at the cost of other public expenditures. The uncontrolled expansion of the self-driving personal vehicle fleet would be equally undesirable, since it would only increase the load on the city's transport system and the overall losses of all traffic participants. This development would lead to a further degradation of the urban environment, which could be prevented by implementing the proposed transport policy measures.

\section{References}

Business Planner (2016) Obshchee issledovanie rynka taksi v Moskve $2016 \mathrm{~g}$. [General taxi market research in Moscow 2016] Available at: https://business-planner.ru/articles/analitika/obshhee-issledovanie-rynka-kafe-v-sankt-peterburge-2016-g-2. html, accessed 20.02.2019 (in Russian).

Christensen C.M. (1997) The Innovator's Dilemma. When New Technologies Cause Great Firms to Fail, Boston, MA: Harvard Business School Press. 
Collie B., Rose J., Choraria R., Wegscheider A.K. (2017) The Reimagined Car. Shared, Autonomous, and Electric, Boston, MA: Boston Consulting Group.

Distanz (2017) Metody prognozirovaniya i effektivnye upravlencheskie resheniya [Forecasting methods and effective management solutions]. Available at: https://www.distanz.ru/feed/lectures/metody-prognozirovaniya-i-effektivnye-upravlencheskieresheniya_3771, accessed 20.02.2019 (in Russian).

Fagnant D.J., Kockelman K.M. (2014) The travel and environmental implications of shared autonomous vehicles, using agentbased model scenarios. Transportation Research Part C: Emerging Technologies, vol. 40, pp. 1-13.

Government of Moscow (2016) Moskovskomu karsheringu 1 god [Moscow car sharing is 1 year old]. Available at: https:// docplayer.ru/33593609-Moskovskomu-karsheringu-1-god.html, accessed 20.02.2019 (in Russian).

Government of Moscow (2017a) Itogi raboty transportnogo kompleksa za 2016 god $i$ plany na 2017 god [Results of the work of the transport complex for 2016 and plans for 2017]. Available at: https://www.mos.ru/upload/newsfeed/ presspresentations/2016-170124095036.pdf, accessed 20.02.2019 (in Russian).

Government of Moscow (2017b) Taksomotornye perevozki v gorode Moskve 2011-2016 [Taxi transportation in Moscow 20112016]. Available at: www.transport.mos.ru. Available at: http://transport.mos.ru/common/upload/docs/1470668676_taxi_ ver2_2016.pdf, accessed 20.02.2019 (in Russian).

Gruel W., Stanford J.M. (2016) Assessing the long-term effects of autonomous vehicles: A speculative approach. Transportation Research Procedia, vol. 13, pp. 18-29.

HBR (1999) Harvard Business Review on Managing Uncertainty, Boston, MA: Harvard Business School Press.

Hörl S., Ciari F., Axhausen K.W. (2018) Recent perspectives on the impact of autonomous vehicles (IVT Working Paper 10XX), Zurich: ETH Zurich. Institute for Transport Planning and Systems (IVT).

Hoyle A. (2016) Apple and Google reportedly buying land for autonomous car facilities. CNet, 06.05.2016. Available at: https://www.cnet.com/roadshow/news/apple-and-google-reportedly-buying-land-for-autonomous-car-facilities/, accessed 20.02.2019.

Kockelman K.M., Fagnant D.J. (2015) Preparing a nation for autonomous vehicles: Opportunities, barriers and policy recommendations. Transportation Research Part A: Policy and Practice, vol. 77, pp. 167-181.

Li S., Sui P.-C., Xiao J., Chahine R. (2018) Policy formulation for highly automated vehicles: Emerging importance, research frontiers and insights. Transportation Research Part A: Policy and Practice (in press). Available at: https://www.sciencedirect. com/science/article/pii/S0965856418300430, accessed 20.02.2019.

Litman T. (2016) Well Measured: Developing Indicators for Sustainable and Livable Transport Planning, Victoria, BC (Canada): Victoria Transport Policy Institute.

Llorca C., Moreno A.T., Moeckel R. (2017) Effects of Shared Autonomous Vehicles on the Level of Service in the Greater Munich Metropolitan Area. Paper presented at the International Conference on Intelligent Transport Systems in Theory and Practice, mobil.TUM 2017, 4-5 July 2017, Munich, Germany. Available at: https:/www.msm.bgu.tum.de/fileadmin/w00bvh/www/ publications/moeckel/2017_llorca_etal.pdf, accessed 20.02.2019.

Loeb B., Kockelman K.M., Liu J. (2018). Shared autonomous electric vehicle (SAEV) operations across the Austin, Texas network with charging infrastructure decisions. Transportation Research. Part C, vol. 89, pp. 222-233. Available at: http:// isiarticles.com/bundles/Article/pre/pdf/143056.pdf, accessed 20.02.2019.

Martin E., Shaheen S. (2016) Impacts of Car2Go Vehicle Ownership, Modal Shift, Vehicle Miles Traveled, and Greenhouse Gas Emissions, Berkeley: University of California.

Martinez L., Crist P. (2015) Urban Mobility System Upgrade - How shared self-driving cars could change city traffic (International Transport Forum Report), Paris: OECD. Available at: https://www.itf-oecd.org/sites/default/files/docs/15cpb_selfdrivingcars.pdf, accessed 20.02.2019.

Maurer M., Gerdes J.C., Lenz B., Winner H. (eds) Autonomes Fahren. Technische, rechtliche und gesellschaftliche Aspekte, Heidelberg, New York, Dordrecht, London: Springer.

Meyer J., Becker H., Bösch P.M., Axhausen K.W. (2017) Autonomous vehicles: The next jump in accessibilities? Research in Transportation Economics, vol. 62, pp. 80-91. Available at: https://doi.org/10.1016/j.retrec.2017.03.005, accessed 20.02.2019.

Milakis D., Snelder M., Van Arem B., Van Wee G.P., Homem de Almeida Correia G. (2015) Development of automated vehicles in the Netherlands: Scenarios for 2030 and 2050, Delft: Delft University of Technology.

Milakis D., Van Arem B., Van Wee B. (2017) Policy and society related implications of automated driving: A review of literature and directions for future research. Journal of Intelligent Transportation Systems, no 4, pp. 324-348.

Mogridge, M.J.H. (1990) Travel in towns: jam yesterday, jam today and jam tomorrow? London: Macmillan Press.

Moreno A.T., Michalski A., Llorca C., Moeckel R. (2018) Shared Autonomous Vehicles Effect on Vehicle-Km Traveled and Average Trip Duration. Journal of Advanced Transportation, article ID 8969353. Available at: https://doi. org/10.1155/2018/8969353, accessed 20.02.2019.

Morgan Stanley (2013) Autonomous Cars: Self-Driving the New Auto Industry Paradigm, New York: Morgan Stanley.

Mosquet X., Zablit H., Dinger A., Xu G., Andersen M., Tominaga K. (2018) The Electric Car Tipping Point. The Future of Powertrains for Owned and Shared Mobility, Boston, MA: The Boston Consulting Group. Available at: https://www.bcg.com/ publications/2018/electric-car-tipping-point.aspx, accessed 20.02.2019. 
OECD (2015) A New Paradigm for Urban Mobility (International Transport Forum Report), Paris: OECD Available at: https:// www.itf-oecd.org/sites/default/files/docs/cop-pdf-03.pdf, accessed 20.02.2019.

Parfenov G. (2017) Potentsial'nye vozdeistviya bespilotnogo transporta [The potential impact of self-driving vehicles], Moscow: HSE (in Russian).

PwC (2016) Stoimost' vladeniya legkovym avtomobilem v Rossii, 2016 [The cost of owning a car in Russia, 2016], Moscow: PwC Russia. Available at: https://www.pwc.ru/en/automotive/publications/assets/costofcar_2016.pdf, accessed 20.02.2019 (in Russian).

PwC (2017) Rynok legkovykh i kommercheskikh avtomobilei v Rossii. Rezul'taty 2016 g. i perspektivy razvitiya [The market for cars and commercial vehicles in Russia. Results for 2016 and development prospects], Moscow: PwC Russia. Available at: https://docplayer.ru/27276592-Rynok-legkovyh-i-kommercheskih-avtomobiley-v-rossii-rezultaty-8-mesyacev-2016-g-iperspektivy-razvitiya.html, accessed 20.02.2019 (in Russian).

Skinner R., Bidwell N. (2016) Making better places: Autonomous vehicles and future opportunities, London: WSP, Parsons Brinckerhoff, Farrels. Available at: http://www.wsp-pb.com/Globaln/UK/WSPPB-Farrells-AV-whitepaper.pdf , accessed 20.02.2019.

Smith C. (2016) Turning Transportation. Challenges and Opportunities Presented to the City of Vancouver by Autonomous Vehicles, Vancouver: University of British Columbia.

Straub E.R., Schaefer K.E. (2018) It takes two to tango: Automated vehicles and human beings do the dance of driving - four social considerations for policy. Transportation Research Part A: Policy and Practice (in press). Available at: https://doi. org/10.1016/j.tra.2018.03.005, accessed 20.02.2019.

Ticoli D. (2015) Driving Changes: Automated Vehicles in Toronto, Toronto: University of Toronto.

Tomtom (2017) HD MAP - Highly accurate border-to-border model of the road. Available at: http://download.tomtom.com/ open/banners/HD-Map-Product-Info-Sheet-improved-1.pdf, accessed 20.02.2019.

van den Berg V.A.C., Verhoef E.T. (2016) Autonomous cars and dynamic bottleneck congestion: The effects on capacity, value of time and preference heterogeneity. Transportation Research Part B: Methodological, vol. 94, pp. 43-60.

WEF, BCG (2015) Self-Driving Vehicles in an Urban Context, Boston, MA: World Economic Forum, Boston Consulting Group. Zakharenko R. Self-driving cars will change cities. Regional Science and Urban Economics, vol. 61, issue C, pp. $26-37$. 